\title{
A Brief Review on Electrode Materials for Supercapacitor
}

\author{
Zaharaddeen S. Iro, C. Subramani ${ }^{*}$ S.S. Dash \\ Department of Electrical and Electronics Engineering, SRM University, Kattankulathur, India 603203. \\ *E-mail: csmsrm@gmail.com
}

doi: $10.20964 / 2016.12 .50$

Received: 5 April 2016 / Accepted: 15 September 2016 / Published: 10 November 2016

\begin{abstract}
One of the issues recently faced in electrostatic field is storage. With recent advances in this area it has become necessary to find an alternative which lead to emergence of supercapacitor. Supercapacitor shares the same fundamental equations as conventional capacitors; to attain higher capacitances supercapacitor uses electrodes having high specific surface area and thinner dielectrics. With these properties it makes them have power densities greater than those of batteries and energy density greater than those of conventional capacitors. Since supercapacitor is mainly a pulse current device it is best used with devices that require high current for short duration of time. Researchers being carried out now are on how to improve the energy density so that they can be used in wider range of applications. The performance of supercapacitor relies on factors such as electrochemical properties of electrode materials used, electrolyte and voltage range. However, most researches are focused on the development of new electrode materials that will yield better performances. In this review paper, storage principle and characteristics of electrode materials such as carbon based materials, metal oxides and conducting polymers in supercapacitors have been reported.
\end{abstract}

Keywords: Supercapacitors, EDLC, Pseudocapacitors, CNTs, Graphene, Ruthenium oxide, PANI.

\section{FULL TEXT}

(C) 2016 The Authors. Published by ESG (www.electrochemsci.org). This article is an open access article distributed under the terms and conditions of the Creative Commons Attribution license (http://creativecommons.org/licenses/by/4.0/). 